To appear (2009) in Phonological Strength, ed. by K. Nasukawa and P. Backley. New York: Mouton de Gruyter.113-149.

Revised July 2008

\title{
Developmental shifts in phonological strength relations
}

\author{
Daniel A. Dinnsen and Ashley W. Farris-Trimble
}

\section{Introduction}

This paper presents evidence from young children's developing phonologies that would seem to be at odds with widely held assumptions about the relative strength of phonological contexts in fully developed languages. More specifically, the evidence suggests that children in the early stages of acquisition can and do merge multiple contrasts across different feature classes in presumably strong contexts (e.g., word-initially) while maintaining those same distinctions in other presumably weak contexts. This disparity is especially problematic for theories that make strong universal claims of continuity between developing and fully developed languages and incorporate learnability considerations for the assessment of explanatory adequacy. We offer a solution to this problem that appeals to a developmental shift in prominence and is cast in terms of the general framework of optimality theory (e.g., Prince and Smolensky 1993/2004).

It is generally acknowledged among phonologists that different positions within the word often behave differently depending on the relative strength of that context. For example, contexts such as the initial position of a syllable, foot, and word have been found cross-linguistically to favor the preservation of phonological contrasts and resist neutralization processes (e.g., Beckman 1998; Lombardi 1999; de Lacy 2002; Smith 2002). Those contexts are judged to be strong, perceptually salient, or prominent. While other contexts can also support phonological contrasts, they are considered to be weaker because they are more vulnerable to neutralization processes that merge underlying distinctions. Some of those weaker contexts include syllable-final, word-final, and foot-medial positions. This dichotomy of strong and weak contexts has several consequences. First, it explains why, for example, so many languages have phonological processes that neutralize voice, place, and manner contrasts only in word-final or syllable-final contexts or why in some languages there might be prohibitions against place features in codas or against coda consonants altogether, or why in heterosyllabic consonant clusters, it is usually the onset consonant that triggers regressive assimilation (rather than the coda that triggers progressive 
Daniel A. Dinnsen and Ashley W. Farris-Trimble

assimilation). This contextual dichotomy is suggestive of the tendency or implicational universal in (1):

(1) Strength/contrast implicational relationship

The occurrence of a contrast in a weak context implies its occurrence in a strong context, but not vice versa.

Following from this implicational generalization are the typological predictions in (2) concerning the presence/absence of a contrast in different contexts:

(2) Typological predictions

There are languages in which a particular feature

a. fails to contrast in any context (strong or weak),

b. contrasts only in a strong context, or

c. contrasts in all contexts (strong and weak).

But, there are no languages in which

d. a contrast is maintained only in a weak context.

These predictions have largely been borne out by investigations of fully developed languages. Even the few apparent exceptions (e.g., Parker 2001; Steriade 2001) end up supporting an asymmetrical typology in which one of the logical possibilities does not occur. Consider, for example, Steriade's (2001) claim that the preferred (strong, perceptually salient) context for maintaining an apical contrast between plain and retroflex consonants is in postvocalic position. She has observed that there are three basic types of languages relevant to this particular contrast, namely (a) those that maintain an apical contrast in both post- and prevocalic contexts (e.g., Djinang), (b) those that maintain the contrast in postvocalic, but not prevocalic contexts (e.g., Murinbata and Miriwung), and (c) those that maintain the contrast in neither post- nor prevocalic contexts (e.g., English). Importantly, no language has yet been identified that maintains an apical contrast prevocalically without also maintaining that contrast postvocalically. Thus, while the details of the typology for an apical contrast may differ from most other contrasts, the same contextual asymmetry still holds such that the occur- 
rence of a contrast in a certain context (i.e., a presumably weak context) implies its occurrence in other (stronger) contexts, but not vice versa. Consequently, the typology in (2) would accurately describe the facts about apical contrasts, provided that the strength of a context is relativized to certain specific featural contrasts.

The more serious problem for contextual strength relations, at least as we see it, is that some children's developing phonologies provide evidence of precisely what does not occur in fully developed languages. More specifically, Dinnsen and Farris-Trimble (2008) have shown that some children merge a single voice, place, or manner contrast in word-initial position while maintaining that same contrast in the presumably weaker postvocalic context. That empirical finding poses a number of theoretical challenges, which are further compounded by the findings to be presented in this paper. The theoretical problem is this: On the one hand, the facts from both developing and fully developed languages when taken together would seem to completely undermine any sense of contextual strength since all contexts appear to be equally vulnerable to phonological mergers, and no context can be singled out as preferred for preserving a phonological contrast. All of the logical possibilities seem to occur. This does, however, treat as accidental the otherwise well established contextual asymmetry that has been observed in fully developed languages. On the other hand, contextual strength may be a valid, legitimate construct that is instantiated one way in fully developed languages and a different way in developing phonologies. The problem with this is the challenge it poses for the continuity hypothesis (Pinker 1984), which maintains that the grammars of developing and fully developed languages are constructed from the same building blocks and are governed by the same grammatical principles. ${ }^{1}$ We thus might have expected developing and fully developed phonologies to deal with phonological strength in the same way. This problem is especially acute for the framework of optimality theory (e.g., Prince and Smolensky 1993/2004), which employs a finite set of universal constraints as one of the central constructs for the expression of all significant generalizations. The assumption is that the constraints are the same for both children and adults and that different language-specific rankings of those constraints should converge on the same common typology of possible grammars. The challenge then is to reconcile the apparent disparity in phonological strength that occurs across developing and fully developed phonologies.

We attempt here to resolve these various problems in a way that acknowledges the significant role of contextual strength relations while also abiding by the continuity hypothesis. Our contention is that the strength of 
a phonological context changes with development. In the early stages, the grammar assigns strength or prominence to final position by default. This will be reconciled with seemingly contradictory phenomena in $\$ 2.4$ and $\S 4.4$. In later stages of development and in fully developed languages, prominence shifts to initial position. We hypothesize that the shift is triggered, in part, by the lexical restructuring that occurs in response to increases in the size of the lexicon as more and more words are added to the child's vocabulary. Our solution is modeled in optimality theoretic terms, but its general insights should extend to other frameworks as well. Our proposal introduces a new set of conflicting universal markedness constraints. These new constraints assign or license prominence in different prosodic contexts. The ranking of those prominence-assigning constraints determines which contexts are strong. The default ranking leads to final prominence, and the reverse ranking results in initial prominence. The change in ranking is triggered in part by changes in the lexicon. The consequence is that continuity can be preserved across developing and fully developed phonologies with differences being attributed to language-specific rankings of universal constraints.

This paper is organized as follows: In §2, we expand on our previous findings by presenting several new case studies of young children who are acquiring English. Each child was selected to illustrate the merger of multiple contrasts, all of which are restricted to a single, presumably strong context, namely word-initial position. Each child also preserved those same contrasts in other contexts, especially in the presumably weak context of word-final position. One of the novel contributions of this paper is its focus on multiple mergers in the same context in a given child's phonology. This is important and goes beyond our earlier work because it shows that the contextual restriction is a property of the child's larger phonological system and not just a peculiarity of a single process or featural contrast. These cases also serve to further instantiate the typological anomaly, which finds contrasts being merged in what otherwise is considered a strong context while also being preserved in a presumably weak context. In $\S 3$, we summarize our earlier optimality theoretic solution to this general problem and show how that proposal also accounts for multiple mergers within a given phonology. This is achieved by illustrating the account for one of the case studies reported here. $\S 4$ considers independent evidence supporting our hypotheses along with a discussion of some unresolved issues. Finally, §5 concludes the chapter with a brief summary. 


\section{The typological problem: Word-initial mergers and final contrast}

The case studies presented in this section exemplify the typological problem posed by some children's developing phonologies. Each child will be shown to exhibit multiple independent phonological processes merging two (or more) contrasts in word-initial position while maintaining those contrasts elsewhere within the word. The data were drawn from the Developmental Phonology Archive at Indiana University. For a fuller description of the Archive; participant characteristics; the methodologies for data elicitation, transcription, and analysis; and for some recent results, see Dinnsen and Gierut (2008). In brief, the Archive includes data on nearly 300 children with phonological delays between the ages 3;0 (years; months) and $7 ; 0$. All of the children are typically developing in every respect, except for evidence of a phonological delay. They scored within normal limits on all standardized tests of hearing, oral-motor mechanism and functioning, nonverbal intelligence, receptive vocabulary, and expressive and receptive language. However, they scored at or below the $5^{\text {th }}$ percentile on the GoldmanFristoe Test of Articulation (Goldman and Fristoe 1986). A comprehensive speech sample was elicited from each child in a spontaneous picturenaming task. Pictures were carefully selected to depict objects and actions known to children of this age and to sample all phonemes of English in initial, medial, and final position. The audio recordings of the children's speech were phonetically transcribed by a trained listener with $10 \%$ of all productions retranscribed for reliability purposes by an independent judge. The overall mean consonant-to-consonant reliability measure was $90 \%$ or better.

Our focus on children with phonological delays may strike some as odd, especially given our interest in unifying accounts of developing and fully developed phonologies. For example, it might be thought that delayed phonologies are inherently aberrant and thus not relevant to the evaluation of typological claims. It should, however, be kept in mind that the only discernable problem for these children was a delay in their phonologies. This determination was, moreover, arrived at based on extensive testing. These children's error patterns thus resemble those of younger, typically developing children. For a fuller discussion of this general issue, see Dinnsen and Gierut (2008), and for examples of typically developing children who exhibit similar error patterns with the same restrictions, see Dinnsen and Farris-Trimble (2008). 


\subsection{Voice and manner contrasts merged/preserved}

The data in (3) are from Child 209 (age 3;5) and are representative of two highly systematic error patterns restricted to word-initial position. One error pattern merges the distinction between voiced and voiceless obstruents by voicing the initial consonant (3a). While the English laryngeal distinction is often referred to in terms of the feature [voice], convincing arguments have been made for the alternative view that the distinction in English is one of aspiration associated with the feature [spread glottis] (e.g., Iverson and Salmons 1995). We will, nevertheless, use the term 'voice' here simply because that is what appears in much of the acquisition literature and is how the children's outputs are typically transcribed. Note that target voiced stops remain voiced (3b). The forms in (3c) show that the laryngeal contrast is preserved postvocalically.

Another independent error pattern replaces word-initial fricatives with a stop. The data in (3d) illustrate this Stopping error pattern. Note that a voiced coronal stop is the substitute for a coronal fricative, and that a voiced labial stop is the substitute for a labial fricative. While voice and manner distinctions are merged in word-initial position, place of articulation is preserved for these sounds. The forms in (3e) establish that stops and fricatives contrast postvocalically.

(3) Child 209 (age 3;5)

a. Initial voiceless stops are voiced

$\begin{array}{llll}{[\text { bai }]} & \text { 'pie' } & {[\text { bid }]} & \text { 'pig' } \\ {[\text { div] }} & \text { 'tear' } & {[\mathrm{di \theta}]} & \text { 'tooth' }\end{array}$

b. Initial voiced stops retain voicing

$\begin{array}{llll}{[\text { but }]} & \text { 'boot' } & {[\text { bait }]} & \text { 'bite' } \\ {[\mathrm{d} \Lambda \mathrm{n}]} & \text { 'done' } & {[\mathrm{d} \text { ir }]} & \text { 'deer' }\end{array}$

c. Voice contrast is preserved postvocalically

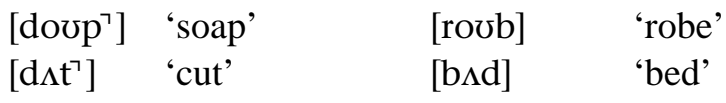


d. Initial fricatives are replaced by stops

$\begin{array}{llll}{[\text { barjø }]} & \text { 'fire’ } & {[\mathrm{bad}]} & \text { 'frog' } \\ {[\text { dæntə] }} & \text { 'Santa' } & {[\mathrm{d} \Lambda \mathrm{ni}]} & \text { 'sunny' }\end{array}$

e. Stops and fricatives contrast postvocalically

$\begin{array}{llll}{[\text { doop'] }} & \text { 'soap' } & {[\text { naif }]} & \text { 'knife' } \\ {[\text { roob }]} & \text { 'robe' } & {[\text { doøv }]} & \text { 'stove' } \\ {[\text { but }]} & \text { 'boot' } & {[\text { mað } \theta]} & \text { 'mouse' } \\ {[\mathrm{m} \Lambda \mathrm{d}]} & \text { 'mud' } & {[\mathrm{b} \Lambda \text { ठ }]} & \text { 'buzz' }\end{array}$

A conventional rule-based account of these phenomena might employ two independent rules, each of which would be restricted to apply exclusively in word-initial position. However, when the same restriction is repeated in different rules in a given grammar (as in the case of Child 209), it would appear that a generalization is being missed. The missed generalization in this instance is that word-initial position is behaving as a weak context with regard to voice and manner distinctions while other positions are behaving as strong contexts for the same features. ${ }^{2}$

\subsection{Place and manner contrasts merged/preserved}

Child 142 (age 4;3) provides evidence of two other independent error patterns that are restricted to word-initial position. One error pattern replaces word-initial affricates with simple alveolar stops (Deaffrication), and the other replaces word-initial alveolar stops with a dorsal consonant when a dorsal occurs later in the word (Consonant Harmony). The relevant data are given in (4).

(4) Child 142 (age 4;3)

a. Word-initial affricates replaced by alveolar stops (Deaffrication)

$\begin{array}{llll}{[\mathrm{tIn}]} & \text { 'chin' } & {[\mathrm{d} \Lambda \mathrm{mp}]} & \text { 'jump' } \\ {[\mathrm{tu}]} & \text { 'chew' } & {[\mathrm{dip}]} & \text { 'jeep’ } \\ {[\mathrm{tIp}]} & \text { 'chip' } & {[\mathrm{d} c \mathrm{t}]} & \text { 'jet’ }\end{array}$


Daniel A. Dinnsen and Ashley W. Farris-Trimble

b. Affricates retained postvocalically

$\begin{array}{llll}\text { [wots] } & \text { 'watch' } & \text { [bwirdz] } & \text { 'bridge' } \\ \text { [pits] } & \text { 'peach' } & \text { [bædz] } & \text { 'badge' } \\ \text { [p } \Lambda \text { ntsin] } & \text { 'punching' } & \text { [oowindzi] } & \text { 'orange-i' }\end{array}$

c. Word-initial alveolar stops assimilate to the place of a following dorsal consonant (Consonant Harmony)

\begin{tabular}{|c|c|c|}
\hline $\mathrm{ks}]$ & ‘ducks’ & {$[g \Lambda k i]$} \\
\hline כq] & 'dog' & [gدgi] \\
\hline gov] & 'tiger' & [kIkIt] \\
\hline
\end{tabular}

d. Fricatives occur word-initially

$\begin{array}{llll}\text { [sæni] } & \text { 'Santa' } & {[\mathrm{s} \Lambda \mathrm{n}]} & \text { 'sun' } \\ \text { [soop] } & \text { 'soap' } & {[\text { sup] }} & \text { 'soup' } \\ \text { [sok] } & \text { 'sock' } & {[\text { sik] }} & \text { 'sick' }\end{array}$

e. Word-initial affricates deaffricate and assimilate to the place of a following dorsal

$\begin{array}{llll}{[\mathrm{kik}]} & \text { 'cheek' } & {[\text { kikın] }} & \text { 'chicken’ } \\ {[\mathrm{kJk}]} & \text { 'chalk' } & {\left[\mathrm{ggkjt}^{\prime}\right]} & \text { 'jacket' }\end{array}$

f. Alveolars and dorsals contrast word-initially and postvocalically in nonassimilatory contexts

$\begin{array}{llll}{[\mathrm{t} \Lambda \mathrm{b}]} & \text { 'tub' } & {[\mathrm{k} \Lambda \mathrm{p}]} & \text { 'cup' } \\ {\left[\mathrm{to \mho}{ }^{\circ} \mathrm{z}\right]} & \text { 'toes' } & {[\mathrm{kovm}]} & \text { 'comb' } \\ {[\mathrm{s} v \mathrm{t}]} & \text { 'foot' } & {[\mathrm{b} v \mathrm{k}]} & \text { 'book' } \\ {[\text { but }]} & \text { 'boot' } & {[\mathrm{wok}]} & \text { 'rock' }\end{array}$

g. Progressive Consonant Harmony blocked

$\begin{array}{llll}{[\text { koot }]} & \text { 'coat' } & {[\mathrm{k} \Lambda \mathrm{t}]} & \text { 'cut' } \\ {[\text { skert }]} & \text { 'skate' } & {[\text { pakst }]} & \text { 'pocket' }\end{array}$


The forms in (4a) illustrate the Deaffrication error pattern in wordinitial position, while those in (4b) show that (alveolar) affricates could occur in postvocalic contexts. The contrast between affricates and stops is thus merged in favor of simple stops in one well-defined context, namely in word-initial position. The Deaffrication error pattern with its restriction to word-initial position is a common phenomenon in children's early phonologies (Smit 1993).

The merger of the place distinction in word-initial position is illustrated by the Consonant Harmony error pattern in (4c). Word-initial alveolar stops are replaced by a dorsal consonant when a dorsal follows later in the word. This error pattern is a typical instantiation of a regressive place assimilation process as described in many other children's phonologies (e.g., Pater and Werle 2003 and references therein). While Consonant Harmony is a common process in developing phonologies, it is acknowledged to be rare or non-occurring in fully developed systems due to the nonlocal domain of the assimilation. This disparity is considered further in $\S 4.5$.

This Consonant Harmony error pattern exhibits several properties that are germane to the main point of this paper. First, this assimilatory process is triggered exclusively by dorsal consonants when they occur in postvocalic (weak) contexts. Note too that word-initial alveolar stops are the only targets of assimilation. The contexts for triggers and targets are just the opposite of what is expected of assimilatory processes in fully developed languages.

The forms in (4d) show that word-initial fricatives are immune to Consonant Harmony. That is, alveolar fricatives can occur in initial position without modification in both assimilatory and non-assimilatory contexts. The contrast between stops and fricatives is thus preserved in that context.

Deaffrication and Consonant Harmony also interact, as can be seen in (4e). That is, both processes are applicable when a word-initial affricate is followed by a dorsal consonant. Under those circumstances, the wordinitial affricate deaffricates and also assimilates to the place of the following dorsal. It is also important to keep in mind that these two processes are independently necessary. That is, there are some words where Deaffrication alone is applicable (4a), and there are other words where only Consonant Harmony is applicable (4c). In these situations, then, each process applies without any potential interference from the other. However, if an affricate assimilates, it also deaffricates.

While the place contrast between coronals and dorsals is merged in word-initial position due to Consonant Harmony, that contrast is preserved in postvocalic contexts (even when a dorsal occurs initially) and in word- 
initial position when the assimilatory trigger is not evident. This is shown in (4f).

The merger of both place and manner distinctions in a presumably strong context and the preservation of those distinctions in weak contexts run counter to standard expectations about contextual strength, at least in fully developed languages. The Consonant Harmony error pattern exhibits the further anomaly that a presumably strong context is giving way to a weak context as a result of assimilation.

\subsection{Multiple voice, place, and manner distinctions merged/preserved}

The data in (5) are from Child 5T (age 4;3) and exemplify a number of common processes, all of which merge particular distinctions exclusively in word-initial position (Gierut 1985). This child combines all of the processes described in the above two case studies plus one other, but does so in a way that yields different results.

(5) Child 5T (age 4;3)

a. Consonant Harmony

$\begin{array}{llll}{[\mathrm{g} \Lambda \mathrm{k}]} & \text { 'duck' } & {\left[\mathrm{g} \mathrm{J}^{\mathrm{w}} \mathrm{g}\right]} & \text { 'dog' } \\ {[\mathrm{g} J \mathrm{gi}]} & \text { 'doggie’ } & & \end{array}$

b. Postvocalic place contrast

$\begin{array}{llll}{[\mathrm{bæk}]} & \text { 'back' } & {[\mathrm{bæt}]} & \text { 'fat' } \\ {[\text { wok }]} & \text { 'rock' } & {[\mathrm{d} \Lambda \mathrm{t}]} & \text { 'cut' }\end{array}$

c. Word-initial Deaffrication and postvocalic affricates

\begin{tabular}{|c|c|c|c|}
\hline [dip] & 'chip' & [wot $\left.\int\right]$ & 'watch' \\
\hline [di:3] & 'cheese' & [bitf] & 'peach' \\
\hline [deli] & 'jelly' & [bid3] & 'bridge' \\
\hline$[\mathrm{d} \Delta \mathrm{mp}]$ & 'jump' & [bædz] & 'badge' \\
\hline
\end{tabular}


d. Word-initial Velar Fronting and postvocalic velars

\begin{tabular}{|c|c|c|}
\hline [dolın] & 'calling' & [bok] \\
\hline$[\mathrm{dx}$. & 'crash' & [woki] \\
\hline$\Delta \Delta b$ & 'glove' & [big] \\
\hline apə] & 'grasshopper' & [bæa] \\
\hline
\end{tabular}

e. Word-initial Stopping and postvocalic fricatives

\begin{tabular}{|c|c|c|c|}
\hline [d $\Lambda \mathrm{n}]$ & 'sun' & [des] & 'dress' \\
\hline [dorp] & 'soap’ & [dus] & 'juice’' \\
\hline$[\mathrm{d} \Lambda \mathrm{bov}]$ & 'shovel' & [bvf] & 'push’ \\
\hline [dæmbu] & 'shampoo' & [wOSIn] & 'washing' \\
\hline$[\mathrm{du}]$ & 'zoo' & 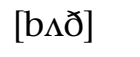 & 'buzz' \\
\hline [dibs] & 'zebra' & [nэљ] & 'noise' \\
\hline
\end{tabular}

f. Word-initial Voicing and postvocalic voice contrast

\begin{tabular}{|c|c|c|c|}
\hline [bvf] & 'push' & [doup] & ‘soap' \\
\hline$s t \theta]$ & 'shirt' & [bigi] & 'piggy' \\
\hline$\Lambda \mathrm{b}]$ & 'tub' & {$[\mathrm{d} \Lambda \mathrm{t}]$} & 'cut' \\
\hline боच] & 'feather' & [bə:də] & 'father' \\
\hline
\end{tabular}

g. Derived alveolar stops immune to Consonant Harmony

\begin{tabular}{|c|c|}
\hline [dor & 'chalk' \\
\hline [dJki] & 'sock-i' \\
\hline
\end{tabular}

The forms in (5a) reflect the basic Consonant Harmony error pattern, which replaces a word-initial alveolar stop with a dorsal when a dorsal consonant follows later in the word. Once again, the target of assimilation must be restricted to the presumably strong context of word-initial position with the trigger being restricted to a presumably weak postvocalic context. The forms in (5b) show that place is indeed contrastive postvocalically. The remaining data illustrate other independent processes that merge wordinitial voice, place, and manner distinctions in favor of alveolar stops. For example, Deaffrication is exemplified in (5c), Velar Fronting in (5d), Stopping in (5e), and Voicing in (5f). Those same data sets show that these error patterns do not affect postvocalic affricates, dorsals, fricatives, and voice- 
less consonants, respectively. Interestingly, the data in (5g) reveal that Consonant Harmony does not operate on alveolar stops that are derived from sources other than target alveolar stops. In a rule-based account of these phenomena, Consonant Harmony would be ordered before all of the other processes in a counterfeeding relation. More importantly, five rules would be required, all of which would have to be crucially restricted to merge contrasts exclusively in word-initial position.

\subsection{Initial consonant omission and postvocalic consonant retention}

It is commonly observed in many fully developed languages that coda consonants are prohibited, resulting in open syllables. It is well known that the presence of coda consonants in a language implies the presence of open syllables in that language, but not vice versa. We might thus expect the marked character of coda consonants to render them vulnerable to deletion, and they certainly are in many children's early speech development. The fact then that Final Consonant Omission is a common error pattern in developing phonologies is entirely consistent with the principles governing fully developed languages. We will return to this point in §4.4. It is also equally well known for fully developed languages that onsetless syllables are marked relative to syllables with onsets. We thus would not expect a child to delete a word-initial consonant to yield a more marked onsetless syllable. However, this is exactly what has been observed in several children's phonologies (Dinnsen and Farris-Trimble 2008 and references therein). We take up here another similar case study involving Child 4 (age $4 ; 2$ ), who omitted initial consonants. The data in (6) exemplify the loss of word-initial consonants and the retention of those same consonants in postvocalic position.

(6) Child 4 (age 4;2)

a. Word-initial consonants omitted

$\begin{array}{llll}{[\mathrm{up}]} & \text { 'soup' } & {[\text { if }]} & \text { 'leaf' } \\ {[æ m p u]} & \text { 'shampoo' } & {[\Lambda \mathrm{n}]} & \text { 'gun' } \\ {[\mathrm{u}]} & \text { 'zoo' } & & \end{array}$


b. Postvocalic consonants retained

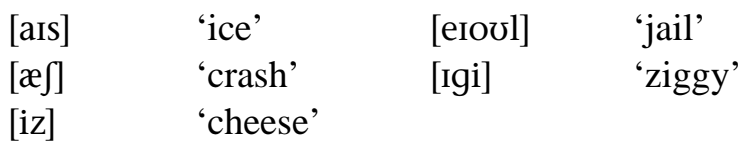

This process of Initial Consonant Omission represents a wholesale merger of many distinctions in a context that might have been thought to resist neutralization. The preservation of postvocalic consonants in itself may not be surprising, but when consonants are preserved in presumably weak contexts, we should expect them to also occur in the perceptually salient context of word-initial position. Admittedly, the process of initial consonant omission is less commonly occurring than the other error patterns discussed in this paper, possibly due to the greater pressure from the target language for syllables to have onsets.

All of the case studies cited here were selected to illustrate the merger of multiple distinctions in word-initial position along with the preservation of those distinctions postvocalically. While these cases came from children with phonological delays, it is important to note that these are not isolated cases and many of the same error patterns and their associated contextual restrictions have also been observed to occur in the early phonologies of children with typical development, although those other reported cases may have focused on the merger/preservation of a single distinction in a given child's phonology (e.g., Dinnsen and Farris-Trimble 2008). The added dimension that is provided by the cases in this paper is that they reveal the contextual restriction to be a pervasive property of the child's grammar cross-cutting several phonological processes. The problem is, however, that the contexts for these mergers and contrasts are just the opposite of what is observed in later stages of development and in fully developed languages. In the next section we take up the solution to this problem and illustrate its implementation with one of the case studies above.

\section{The solution: Conflicting prominence-assigning constraints}

A solution to the general problem posed by the data in $\S 2$ has been put forward in our account of similar phenomena from typical and delayed phonological acquisition (Dinnsen and Farris-Trimble 2008). We recapitulate below some of the essentials of that account and relate it directly to the cases of multiple contextual mergers in §2. 


\subsection{Contextual mergers in optimality theory}

Let us first briefly review how optimality theory deals with contextual mergers in fully developed languages. Two alternative approaches making essentially the same typological predictions have been advanced. One approach relies on a positional faithfulness constraint to preserve a contrast in a prominent context (e.g., Beckman 1998; Lombardi 1999). Under that approach, what serves as a prominent context is stipulated and may be specific to the property to be preserved. The positional faithfulness constraint would be ranked above a general antagonistic markedness constraint that bans some marked structure. That ranking ensures that a contrast is preserved in a prominent context. At the same time, the merger of the contrast in nonprominent contexts would be achieved by ranking the general markedness constraint above a context-free version of the faithfulness constraint. German serves as a standard example of a language that maintains a voice contrast in onsets while merging that contrast in codas. The prominence of onsets and their resistance to mergers with regard to laryngeal features is captured by stipulating the contextual restriction to onsets in the definition of a laryngeal faithfulness constraint (e.g., ID-ONSET[laryngeal]). By ranking the general markedness constraint *LARYNGEAL below the positional faithfulness constraint, the [voice] feature would be preserved in onsets but banned in all other contexts. The following schema serves to illustrate a standard account of the contextual merger of the voice contrast in fully developed languages:

(7) Positional faithfulness and contextual neutralization

$$
\text { ID-ONSET[laryngeal] >> *LARYNGEAL >> ID[laryngeal] }
$$

The alternative approach for dealing with contextual mergers relies instead on a highly ranked markedness constraint that is formulated to ban a marked property in a specific context, i.e., one that is nonprominent or weak. For example, the alternative markedness constraint relevant to the merger of the voice contrast in codas, *VOICED-CODA, simply bans voiced obstruents in codas (e.g., Kager 1999). By ranking ID[laryngeal] between *VOICED-CODA and the context-free version of that constraint, *LARYNGEAL, a contrast is permitted to occur in a prominent onset context but not in the weak coda context. The schema for this alternative approach would entail the following constraints and ranking: 
(8) Contextually conditioned markedness and context-free faithfulness

*VOICED-CODA >> ID[laryngeal] >> *LARYNGEAL

No matter which approach (or combination of approaches) one adopts, the assumption about constraints is that they are generally asymmetric in their substantive formulation. ${ }^{3}$ That is, if some constraint bans a feature in codas, the expectation is that there should be no complementary constraint that is specifically formulated to ban that same feature in the context of onsets. Similarly, if some positional faithfulness constraint demands featural identity between corresponding input and output segments in the prominent context of onsets, no positional faithfulness constraint relating to the same feature would be restricted to the complementary context of codas. The asymmetrical character of many constraints under either approach has the desirable consequence of limiting the typology of possible languages.

Both of these general approaches fail to account for the developmental facts from the prior section. One possible solution might be to give up the asymmetric character of constraints and postulate the existence of additional constraints from the same family with the stipulation of opposite or complementary contextual restrictions. For example, children's acquisition of the voice contrast first in codas and the associated merger of that contrast in word-initial position might seem to require a highly ranked faithfulness constraint stipulating the preservation of the voice contrast in codas while allowing it to be merged in word-initial position due to a lower-ranked markedness constraint. The hypothetical constraint that is called for might be ID-CODA[laryngeal], but that constraint is the complement of what is needed for fully developed languages, namely ID-ONSET[laryngeal], and is otherwise unattested. The same issue arises with regard to constraints involving place and manner contrasts. We could, of course, expand the constraint set to include constraints defined on complementary contexts, but the permutable rankings of these constraints would predict a wider range of variation than has been observed in fully developed languages. This constitutes a serious drawback for this approach.

The facts of fully developed and developing phonologies leave little doubt about the need for contextual restrictions of some kind in the substantive formulation of constraints. The real issue is whether those restrictions need to be stipulated, as has been assumed, and whether the restrictions are the same for developing and fully developed languages. In the next section, we sketch our solution, which derives prominence and retains a universal constraint set that is the same for children and adults. 


\subsection{Prominence-assigning constraints}

The main element of our solution introduces a new set of competing markedness constraints that has the effect of deriving prominence (rather than stipulating it in different constraints). Under this proposal, what serves as a prominent context is derived from the ranking of competing universal markedness constraints given in (9). These markedness constraints are similar to markedness constraints that assign syllable structure. That is, neither syllable structure nor prominence is specified in the input, and both are in one sense derived by constraint interaction. These constraints assign or license prominence in certain prosodic domains. For example, one such markedness constraint from the INITIALPROM family holds at the level of the syllable and would assign prominence to syllable onsets (and only that subsyllabic constituent); the other competing markedness constraint from the FINALPROM family would assign prominence to the complementary subsyllabic constituent, namely rhymes. A candidate incurs a violation of these constraints if it fails to have prominence in the licensed context or if it includes prominence in a context that does not license prominence. Ranking these constraints relative to one another is necessary to resolve the conflict that would arise when prominence occurs in different contexts within the word. By resolving the conflict between these constraints, the desired asymmetries can be achieved.

(9) Prominence-assigning markedness constraints

INITIALPROM: The initial constituent of a syllable, foot, or prosodic word must be prominent

FinALPROM: The final constituent of a syllable, foot, or prosodic word must be prominent

\section{Default ranking: FINALPROM >> INITIALPROM}

Depending on how these markedness constraints are ranked, one or the other context, but not both, would be realized phonetically with prominence. It is assumed that no more than one constituent of a particular prosodic domain can be prominent. This is similar to the restriction that a foot can have no more than one head, and every foot must have a head. We further assume, for reasons to be discussed below, that the default ranking of these markedness constraints results in rhymes being prominent in the initial state. ${ }^{4}$ Clearly, the ranking of these two prominence-assigning marked- 
ness constraints must change over time if the well established prominence of onsets in fully developed languages is to be accounted for. We hypothesize that one possible explanation for the reranking of prominenceassigning constraints may be in response to increases in the size of the lexicon and the need to differentiate words in more densely packed lexical neighborhoods. This hypothesis accords with the widely held developmental perspective that the lexicon undergoes a restructuring that leads to more elaborate, detailed representations (e.g., Walley, Metsala, and Garlock 2003). Additionally, some psycholinguistic studies have documented a developmental shift in the prominence of subsyllabic structures with the early salience of rhymes giving way to more enhanced onsets (see $\S 4.1$ for some highlights from relevant studies and Munson and Babel (2005) for a more thorough review).

Given that the lexicon under normal circumstances does not get smaller as time goes on, no fact would ever motivate a further reranking of the prominence-assigning constraints. Consequently, once onsets have become prominent due to the first reranking of the prominence-assigning markedness constraints, the ranking of these constraints essentially becomes fixed with onsets remaining prominent in fully developed languages.

With the prominence-assigning markedness constraints determining what is prominent, positional faithfulness constraints can then take advantage of that licensed prominence at any stage of development by simply specifying that the faithfulness constraint holds only in a prominent context. We will be formulating our solution in terms of positional faithfulness, but it could as well be recast in contextual markedness terms. ${ }^{5}$ The formulation of positional faithfulness constraints can in turn be constrained or simplified in that the prominence of a specific context would not need to be stipulated; instead, the constraint would simply specify that it is sensitive to prominence at some higher prosodic level (e.g., the syllable, foot, or word). The ranking of the prominence-assigning constraints would determine whether, for example, it is the onset or the coda of a syllable that is rendered prominent.

The following serves as a generic account of the contextual mergers described in $\S 2$. The constraints in (10) are defined in general terms, but they can be instantiated with any of the relevant voice, place, or manner features. Similarly, the prominence-assigning constraint INITIALPROM in (9) above should be interpreted as referring to a family of constraints holding at the level of the syllable, foot, or word. This constraint assigns prominence to the initial constituent of a prosodic category (e.g., either the onset of a syllable, the initial syllable of a foot, or the initial foot of a word). ${ }^{6}$ The 
other family of prominence-assigning constraints, FINALPROM, in (9) refers to the complementary class of constituents within a given prosodic domain (e.g., the syllable rhyme, the final syllable of a foot, or the final foot of a word).

(10) Generic constraints

a. Faithfulness

ID-PROM[feature]: Corresponding segments in prominent contexts must have identical voice, place, or manner features

ID[feature]: $\quad$ Corresponding segments must have identical voice, place, or manner features

b. Segmental/featural markedness

*FEATURE: $\quad$ Voice, place, or manner features are banned

Let us now see how our proposal can be applied to the case of Child 142, who merges certain place and manner contrasts word-initially, but maintains those contrasts elsewhere within the word. The full set of constraints that we will be employing in this case is given in (11).

(11) Constraints and ranking

a. Markedness

AGREE:

Stops with different place features are

*AFFR: banned within the word

INITIALPROM: $\quad$ The initial constituent of a syllable, Affricates are banned

FINALPROM: The final constituent of a syllable, foot, or prosodic word must be prominent

b. Faithfulness

ID-PROM[manner]: Corresponding segments in prominent contexts must have identical manner features

ID-PROM[place]: Corresponding segments in prominent contexts must have identical place features

ID[coronal]: $\quad$ Corresponding segments must be identical in terms of the feature [coronal]

ID[manner]: $\quad$ Corresponding segments must have identical manner features 
c. Ranking:

FINALPROM, ID-PROM[place], ID-PROM[manner] >>

INITIALPROM, AGREE, *AFFR >> ID[manner], ID[coronal]

In accord with assumptions about the initial state and the default ranking of constraints (Smolensky 1996), it is assumed that error patterns arise from the dominance of certain markedness constraints over antagonistic faithfulness constraints. Deaffrication and Consonant Harmony involve changes in manner and/or place features, suggesting that the faithfulness constraints ID[manner] and ID[coronal] are dominated by antagonistic markedness constraints. Beginning with Deaffrication, we saw that the contrast between word-initial affricates and simple alveolar stops is neutralized in favor of the simple alveolar stop. The markedness constraint *AFFR banning affricates would compel a change to a less marked stop if that constraint dominated ID[manner]. For expository purposes, we will consider stops, fricatives, and affricates to differ in manner, even though different features and geometric structures are ultimately involved in their representations. Thus, any change from an affricate to a simple alveolar stop will be considered to violate ID[manner]. The tableau in (12) illustrates the ranking necessary to account for this one aspect of the error pattern.

(12) Deaffrication

\begin{tabular}{|l||c|c|}
\hline$/ \mathrm{t} \int \mathrm{u} /$ 'chew' & $*$ AFFR & ID[manner] \\
\hline a. $\mathrm{t} \int \mathrm{u}$ & $* !$ & \\
\hline b. $\mathrm{tu}$ & & $*$ \\
\hline
\end{tabular}

We are assuming here that this child's input representations are targetappropriate. This is in accord with "Richness of the Base" (Prince and Smolensky 1993/2004), which precludes language-specific (or childspecific) restrictions on input representations. However, even if the input representation for this word were assumed to be identical to the occurring errored output representation, as might follow from lexicon optimization (Prince and Smolensky 1993/2004), it is essential that the constraint hierarchy can guarantee the selection of the attested output. By ranking *AFFR over ID[manner], candidate a with an affricate incurs a fatal violation of the markedness constraint and is ruled out in favor of candidate b no matter which of the alternatives is assumed to be the input representation. 
In order to account for the preservation of affricates in words such as [pits] 'peach', a positional faithfulness constraint is needed that preserves manner in postvocalic contexts. That constraint must also be ranked above the antagonistic markedness constraint *AFFR. This is where we can begin to illustrate the role of the prominence-assigning constraints. Specifically, by appealing to the default ranking of FINALPROM over INITIALPROM, the entire rhyme of a syllable (including specifically the coda consonant) will be rendered prominent. The prominence of that coda establishes it as the proper domain for the positional faithfulness constraint ID-PROM[manner]. The tableaux in (13) show how the manner contrast is preserved postvocalically in 'peach' and merged word-initially in 'chew'. The different possible locations for prominence in the candidate set are indicated by enclosing the prominent segments in parentheses.

It should be kept in mind that freedom of analysis allows candidates to differ solely by their prominence. ${ }^{7}$ Notice, for example, that candidates a and $\mathrm{b}$ are segmentally identical in each tableau, as are c, d, and e, but they differ in the location and presence of prominence, and their wellformedness is evaluated differently by the prominence assigning constraints. Those candidates with initial prominence (a and c) and those with no prominence (e) are assigned fatal violations by FINALPROM and are eliminated from the competition. The positional faithfulness constraint takes advantage of the prominence assigned to the rhyme to rule out candidate $\mathrm{d}$ in the tableau for 'peach' and prevent deaffrication in that context.

(13) Manner contrast preserved postvocalically and merged word-initially

\begin{tabular}{|l||c:c|c:c|c|}
\hline$/ \mathrm{t} \int \mathrm{u} /$ 'chew' & $\begin{array}{c}\text { FINAL } \\
\text { PrOM }\end{array}$ & $\begin{array}{c}\text { ID-PROM } \\
\text { [manner] }\end{array}$ & $\begin{array}{c}\text { INITIAL } \\
\text { PROM }\end{array}$ & $*$ AFFR & ID[manner] \\
\hline \hline a. $\quad(\mathrm{t}) \mathrm{u}$ & $* !$ & & & $*$ & \\
\hline b. $\mathrm{t} \int(\mathrm{u})$ & & & $*$ & $* !$ & \\
\hline c. $\quad(\mathrm{t}) \mathrm{u}$ & $* !$ & $*$ & & & $*$ \\
\hline d. $\mathrm{t}(\mathrm{u})$ & & & $*$ & & $*$ \\
\hline e. tu & $* !$ & & $*$ & & $*$ \\
\hline
\end{tabular}




\begin{tabular}{|l||c:c|c:c|c|}
\hline$/$ pitf/ 'peach' & $\begin{array}{c}\text { FINAL } \\
\text { PROM }\end{array}$ & $\begin{array}{c}\text { ID-PROM } \\
\text { [manner] }\end{array}$ & $\begin{array}{c}\text { INITIAL } \\
\text { PROM }\end{array}$ & $*$ AFFR & ID[manner] \\
\hline \hline a. (p)its & $* !$ & & & $*$ & \\
\hline b. p(its $)^{2}$ & & & $*$ & $*$ & \\
\hline c. (p)it & $* !$ & & & & $*$ \\
\hline d. p(it) & & $* !$ & $*$ & & $*$ \\
\hline e. pit & $* !$ & & $*$ & & $*$ \\
\hline
\end{tabular}

Moving now to this child's Consonant Harmony error pattern, note that a change in a place feature is involved, namely the change from an alveolar stop to a dorsal when followed by a dorsal consonant. Alveolars are the only place of articulation vulnerable to change; labial and dorsal stops are never realized unfaithfully as a result of Consonant Harmony or any other process. We thus assume, independent of any assigned prominence, that one or more undominated context-free faithfulness constraints preserve underlying input labial and dorsal place in all contexts (e.g., de Lacy 2002). These constraints will not be mentioned further, but they contribute to the explanation for why dorsals (but not coronals) trigger Consonant Harmony and why labials are not targets of Consonant Harmony. The contextually conditioned markedness constraint AGREE compels Consonant Harmony by banning alveolar stops when a different place feature occurs within the word, provided that this constraint also dominates the antagonistic faithfulness constraint ID[coronal]. Notice that AGREE assigns a fatal violation mark to the faithful candidate with this ranking.

(14) Consonant Harmony

\begin{tabular}{|l||c|c|}
\hline$/ \mathrm{d}$ g/ 'dog' & AGREE & ID[coronal] \\
\hline \hline a. dog & $* !$ & \\
\hline b. gog & & $*$ \\
\hline
\end{tabular}

The above account does not yet explain the regressive versus progressive character of Consonant Harmony. Consider, for example, words such as [kovt] 'coat', which do not undergo Consonant Harmony and are realized faithfully by this child. In the absence of any other constraints, the final alveolar stop of the faithful candidate would cause a fatal violation of AGREE, incorrectly predicting progressive Consonant Harmony as well as regressive Consonant Harmony. By appealing to the default ranking of the 
prominence-assigning constraints (as required for the facts about the manner contrast for this child) and by ranking the positionally restricted faithfulness constraint ID-PROM[place] above AGREE, place features in final prosodic constituents will always be preserved. This point is illustrated in the tableaux in (15).

(15) Progressive Consonant Harmony blocked

\begin{tabular}{|c||c:c|c:c|c|}
\hline$/$ /kout/ 'coat' & $\begin{array}{c}\text { FINAL } \\
\text { PrOM }\end{array}$ & $\begin{array}{c}\text { ID-PrOM } \\
\text { [place] }\end{array}$ & $\begin{array}{c}\text { INITIAL } \\
\text { PROM }\end{array}$ & AGREE & ID[coronal] \\
\hline \hline a. (k)out & $* !$ & & & $*$ & \\
\hline b. ${ }^{*} \mathrm{k}$ (out) & & & $*$ & $*$ & \\
\hline c. (k)ouk & $* !$ & & & & $*$ \\
\hline d. k(ouk) & & $* !$ & $*$ & & $*$ \\
\hline
\end{tabular}

\begin{tabular}{|c|c|c|c|c|c|}
\hline /dug/ 'dog' & $\begin{array}{l}\text { FINAL } \\
\text { PROM }\end{array}$ & $\begin{array}{c}\text { ID-PROM } \\
\text { [place] }\end{array}$ & $\begin{array}{l}\text { INITIAL } \\
\text { PROM }\end{array}$ & AGREE & ID[coronal] \\
\hline $\begin{array}{ll}\text { a. } & \text { (d)xg }\end{array}$ & $* !$ & & & * & \\
\hline b. $\quad d(J g)$ & & & * & $* !$ & \\
\hline c. $\quad(g) x g$ & $* !$ & $*$ & & & $*$ \\
\hline d. $\mathrm{g}(\mathrm{Jg})$ & & & * & & $*$ \\
\hline e. $\quad(d) x d$ & $* !$ & & & & $*$ \\
\hline f. $\quad$ d(od) & & $* !$ & * & & * \\
\hline
\end{tabular}

Notice in particular that ID-PROM[place] eliminates candidate $f$ due to changes in the place features of prominent codas.

It is a simple matter now to see how the account works for words where Deaffrication and Consonant Harmony interact. The tableau in (16) considers the realization of a word such as 'cheek', adopting the combined set of constraints and ranking from above. Due to space limitations, we have excluded from the tableau the two low-ranked faithfulness constraints ID[coronal] and ID[manner] because their violations are not crucial. Undominated FINALPROM assigns fatal violation marks to all candidates in which the rhyme (especially the coda consonant) is not prominent. Given that onsets cannot be prominent, the positional faithfulness constraints will not be able to preserve the place or manner of the word-initial affricate. The markedness constraint AGREE will thus eliminate the faithful candidate with an initial affricate and the unassimilated candidate with a word-initial 
simple alveolar stop. Any candidate like $\mathrm{f}$ in which the final consonant assimilates to the place of the initial consonant will be eliminated by undominated ID-PROM[place]. Candidate h thus survives as optimal.

(16) Interaction of Deaffrication and Consonant Harmony

\begin{tabular}{|c|c|c|c|c|c|c|}
\hline /t $\int \mathrm{ik} /$ 'cheek' & $\begin{array}{l}\text { FINAL } \\
\text { PROM }\end{array}$ & $\begin{array}{c}\text { ID-PROM } \\
\text { [place] }\end{array}$ & $\begin{array}{l}\text { ID-PROM } \\
\text { [manner] }\end{array}$ & $\begin{array}{c}\text { INITIAL } \\
\text { PROM }\end{array}$ & AGREE & *AFFR \\
\hline a. $\quad(\mathrm{t}$ ) $) \mathrm{ik}$ & $* !$ & & & & $*$ & $*$ \\
\hline b. $\quad \mathrm{t} \int(\mathrm{ik})$ & & & & $*$ & $* !$ & $*$ \\
\hline C. $\quad(\mathrm{t}) \mathrm{ik}$ & $* !$ & & $*$ & & $*$ & \\
\hline d. $\quad$ t(ik) & & & & $*$ & $* !$ & \\
\hline e. $(t) i t$ & $* !$ & & $*$ & & & \\
\hline f. $\quad$ t(it) & & $* !$ & & $*$ & & \\
\hline g. (k)ik & $* !$ & $*$ & $*$ & & & \\
\hline h. $\mathrm{k}(\mathrm{ik})$ & & & & $*$ & & \\
\hline
\end{tabular}

While this case and the others from §2 involved multiple mergers in the same context, one and the same set of prominence-assigning constraints was employed to designate final prosodic constituents as prominent. All of the mergers were sanctioned in nonprominent (initial) contexts, and all contrasts were preserved due to positional faithfulness constraints that were sensitive to prominence. Those faithfulness constraints are exactly the same positional faithfulness constraints employed in fully developed languages, but their implementation is different due to the particular ranking of the prominence-assigning constraints.

The above account is a particular instantiation of what would be required generally for the cases presented in $\S 2 .{ }^{8}$ This even extends to the somewhat unusual error pattern of Initial Consonant Omission (Child 4, §2.4). For example, instead of featural faithfulness constraints being involved in that case, the deletion of whole segments implicates the violation of the low-ranked anti-deletion constraint MAX. Notice that MAX is not restricted by context. Context-free markedness constraints banning various classes of sounds must be ranked above MAX to compel deletion. The preservation of consonants in postvocalic contexts can come about from undominated FINALPROM and an anti-deletion constraint that is sensitive to prominence, namely MAXPROM. This positional faithfulness constraint prohibits deletion in the prominent part of a syllable, foot, or prosodic 
word. In this particular instance the prominent part of the syllable is the rhyme. By ranking MAXPROM over the markedness constraints, consonants will be preserved in the more prominent postvocalic context, but will be deleted word-initially because that context was not assigned prominence by undominated FINALPROM.

The consequence is that all of the typologically problematic cases in §2 can be fit within the general schema in (17).

(17) Schema for cases in §2

FINALPROM, ID-PROM[feature] >> INITIALPROM, *FEATURE >> ID[feature]

We have argued elsewhere (Dinnsen and Farris-Trimble 2008) that this schema represents an early intermediate stage of development. More specifically, it fits within a plausible developmental trajectory. Earlier stages of development would be consistent with the default ranking of markedness over (prominence-sensitive) faithfulness. FINALPROM would, of course, outrank INITIALPROM at that earlier point as well. The empirical consequence is that one or more contrasts would be merged in all contexts. This is typical of children who completely exclude certain sounds from their inventories. The early intermediate stage of development that we have been focusing on in this paper derives from that earlier stage by the simple demotion of one or more markedness constraints below the prominencesensitive faithfulness constraint. A later intermediate stage of development is identical to the schema in (17) above, except that FINALPROM is demoted below INITIALPROM. Such a stage of development begins to look more like fully developed languages, where contrasts are preserved word-initially but merged postvocalically. The end-state stage of development results from the demotion of markedness below faithfulness, yielding contrasts in all contexts.

\section{Discussion}

This section highlights some independent support for our hypotheses and considers some issues that arise from those proposals. 


\subsection{Psycholinguistic support}

The facts considered thus far have largely involved conventional linguistic evidence regarding children's synchronic grammars. However, two recent psycholinguistic studies are especially relevant to our proposals about the early prominence of rhymes and the reranking of prominence-assigning markedness constraints. Both studies provide external evidence of a developmental shift in the prominence of children's subsyllabic structures. In the first study, Brooks and MacWhinney (2000) report results from two experiments that were designed to test the effects of interfering primes in different age groups. They compared the effects of auditorily presented words with onset prime and rhyme prime in a picture-naming task. Thirty participants in four age groups (5 years, 7 years, 9+ years, and college undergraduates) were divided into two groups. Participants were asked to name a picture after being presented auditorily with a stimulus word which was either identical to the picture, phonologically related, phonologically unrelated, or neutral. Of the phonologically related words, half of the participants received words that shared an onset with the picture word and half received words that shared a rhyme with the picture word. The 5-year-old children's picture naming was faster when they were presented with a rhyme prime word than with an onset prime word. Seven-year-old children showed equal facility for the two sets of words, while older children's and adults' productions were better facilitated by onset prime words. Brooks and MacWhinney conclude that there is a developmental change in speech production strategies - as children grow older, they restructure their lexicons in order to facilitate incremental production. As a default, though, young children's productions are most strongly influenced by the rhyme.

In another series of experiments, Coady and Aslin (2004) performed nonword repetition tasks with two groups of twelve children, ages 2;6 and 3;6. Both groups of children more accurately repeated 2- and 3-syllable nonwords that contained high frequency phonemes than they did nonwords that contained low frequency phonemes. However, in a second study, Coady and Aslin found that only the older set of children more accurately repeated nonwords in which the frequency difference occurred only in syllable onsets. The younger children showed no difference in accuracy in these words. Coady and Aslin concluded that while all the children were sensitive to the relative frequency of segments, only the older children were sensitive to more fine-grained frequency differences in onset position. 
We take the findings of a developmental shift in the prominence of subsyllabic structures to reflect our proposed reranking of the prominenceassigning constraints and to be supportive of our claim that the default is for rhymes to be prominent in the early stages of acquisition.

\subsection{Other evidence for the prominence of rhymes}

Acquisition researchers have long recognized the perceptual salience of final position for young children (e.g., Slobin 1973; Echols and Newport 1992). Another piece of evidence for the default prominence of rhymes relates to the fact that vowels tend to be produced more accurately than onset consonants in the early stages of acquisition (e.g., Pollock and Keiser 1990; Otomo and Stoel-Gammon 1992; Pollock and Berni 2003).

There is also some evidence that the prominence of rhymes persists for some phenomena, even after there has been a general shift of prominence to onsets for other phenomena. This is exemplified by onset structures that are dependent on an aspect of rhyme structure. That is, on the basis of crosslinguistic and developmental evidence, it has been observed that the occurrence of certain onset clusters in a language depends on the occurrence of complex (branching) rhymes in that language (e.g., Lleó and Prinz 1996; Baertsch 2002; Kirk and Demuth 2003; Kehoe and Hilaire-Debove 2004; Levelt and van de Vijver 2004). A promising optimality theoretic proposal for capturing this dependency is embodied in the "split margin hierarchy" (Baertsch 2002 and Baertsch and Davis in this volume). Under this proposal, the occurrence of an onset stop+liquid cluster depends on the occurrence of a coda liquid consonant. The developmental prediction would also be that a stop+liquid cluster cannot be acquired without first having acquired a coda liquid consonant. For an overview and critique of the split margin hierarchy as it relates to acquisition, see Barlow and Gierut (2008). Independent of the theoretical account that one might adopt, the persistent dependency of onsets on rhymes can be seen as a possible remnant of the early developmental prominence of rhymes. That is, the early prominence of rhymes predicts that marked structures should arise first in rhymes and only later in onsets. 


\subsection{Lexical restructuring and richness of the base}

Our proposal about the reranking of the prominence-assigning constraints was tied, in part, to the widely held view among acquisition researchers that children's lexical representations and the organization of their lexicons undergo a restructuring in the early stages (Charles-Luce and Luce 1990; Metsala and Walley 1998; Storkel 2002; Walley, Metsala, and Garlock 2003). The general assumption has been that children begin with more holistic, syllable-sized representations. Those representations are presumed to be coarsely coded, underspecified, or otherwise unanalyzable. As new words are added to the lexicon and more and more words need to be differentiated, representations begin to restructure, becoming more elaborated or more fully specified. This developmental perspective might seem at odds with a basic tenet of optimality theory, namely richness of the base. The assumption of optimality theory is that input representations are universal and are thus the same for children and adults. Children's underlying representations should not be subject to change - contrary to what has typically been assumed by acquisition researchers. These seemingly incompatible positions can, however, be reconciled within optimality theory without violating richness of the base. That is, even during the earliest stages of acquisition, highly elaborate, adult-like, unchanging input representations can be adopted, if the markedness constraints that militate against structure outrank the faithfulness constraints. This is assumed to be the default ranking of constraints, and it mimics what would appear to be simple, underspecified representations. Over time, as markedness constraints are demoted on the basis of positive evidence, more elaborate representations are permitted to surface, revealing the rich base. Under this view, then, it is not the representations per se that change, but rather the constraint hierarchy. In this way, changes in the constraint hierarchy can be equated with apparent lexical restructuring. Consequently, when we talk about the reranking of the prominence-assigning constraints being triggered by lexical restructuring, this should more properly be interpreted to mean that the prominenceassigning constraints rerank in response to increases in the size of the lexicon, which in turn brings on other changes in the constraint hierarchy to yield the effect of lexical restructuring.

Our conjecture about the role of vocabulary size is supported by a recent study by Smith, McGregor, and Demille (2006). They collected spontaneous language samples from three groups of typically developing children: 2-year-olds with average-sized vocabularies (approximately 330 words), age-matched peers with precocious vocabularies (approximately 
590 words), and older children (age 2;6) with average-sized vocabularies (approximately 562 words). Phonological performance was measured in a variety of ways, including the number of different consonants that were targeted, the number of different consonants produced correctly, and the percentage of consonants produced correctly. The lexically precocious 2year-olds were found to be similar to their older vocabulary mates on most measures of phonological performance, and both of these groups were generally superior to the 2-year-olds with smaller lexicons. These findings offer some support for a hypothesized relationship between lexicon size and phonological performance, and suggest that 2-year-olds' phonological development is more closely related to size of the lexicon than to chronological age.

\subsection{Prominent rhymes and final consonant omission}

One of our central claims is that rhymes are rendered prominent in the initial state as a result of the default ranking of the prominence-assigning constraints. This might, however, seem at odds with the fact that many children in the early stages of acquisition omit coda consonants. Why would a child omit coda consonants if rhymes were truly prominent? This is reconciled by appealing to the independent and freely permutable markedness constraint NOCODA, which bans coda consonants. When NOCODA is ranked above the antagonistic faithfulness constraint, MAX, which militates against deletion, coda consonants would be omitted, even if FINALPROM were ranked above INITIALPROM. It is important to keep in mind that the prominence-assigning constraints conflict with one another, but they do not conflict with other segmental/featural markedness or faithfulness constraints. There is thus no antagonism between the prominence of rhymes and the presence/absence of coda consonants. The situation we are entertaining here is analogous to the initial state where FINALPROM outranks INITIALPROM and markedness dominates faithfulness. On the other hand, when NOCODA is demoted below MAX, coda consonants would be preserved independent of the ranking of the prominence-assigning constraints. Importantly, the early demotion of NoCODA during the stages when rhymes are prominent should result in the emergence of segmental contrasts first in rhymes. It is, of course, possible that NoCODA could be demoted late in the course of acquisition - after many segmental contrasts had already been established in onsets. In such a situation, it might mistakenly appear that our predictions were not supported because rhymes would lag behind on- 
sets in the order and number of acquired contrasts. However, to properly evaluate our hypothesized developmental trajectory, it is important to identify a child who has demoted NoCODA early in the course of acquisition before onsets and codas compete for featural contrasts.

\subsection{Some unresolved issues}

While our proposals solve certain problems, they also raise other questions and point to some promising areas in need of further research. For example, our proposal about the reranking of the prominence-assigning constraints raises questions about the nature of the evidence needed to trigger the reranking. We speculated that the reranking might be triggered by increases in the size of the lexicon. More psycholinguistic research is also called for to determine whether there is a developmental shift in the prominence of other prosodic constituents beyond the onset and rhyme. These questions highlight the need for more studies that are specifically designed to focus on the interaction between children's error patterns and the structure and organization of their lexicons.

Another issue that arises is whether some contexts are invariably prominent for certain featural contrasts. As we have formulated our proposal, the prominence-assigning constraints are freely permutable, at least to a certain extent, predicting that complementary contexts can be prominent either at different stages of development or in different children. However, returning to Steriade's (2001) claims about the salience of postvocalic contexts for apical contrasts, it would appear that the prominence of that context may not change for that contrast (although she presented no developmental data on this point). If it were to turn out that certain contexts are invariably prominent for certain contrasts, it may be desirable to distinguish those from others that are vulnerable to a shift in prominence. This might be done by postulating positional faithfulness constraints that are restricted to those specific invariant features and contexts.

As a further test of this prediction, it will be important to determine whether there are cases where a child might, for example, merge one contrast in initial position and merge a different contrast in final position. If such cases were found, it would be necessary to modify our proposal. One possible approach to this question might be to reformulate the prominenceassigning constraints with each relativized to specific features. It is unclear at present whether such an elaboration is necessary or desirable.

The prominence paradox is just one of several known disparities between developing and fully developed languages. Our proposal for dealing 
with this disparity may hold promise for resolving others. For example, one routinely cited difference relates to the phenomenon of long-distance consonant harmony commonly observed in developing (but not fully developed) phonologies (cf. Child 142 in §2.2 and Child 5T in §2.3). The widely held assumption is that assimilation is local with the trigger and target being adjacent (Níchiosáin and Padgett 2001). The nonlocal character of children's consonant harmony processes challenges this assumption. Feature geometry with its hierarchical organization of features and autonomous tiers offers a structural means for characterizing limits on assimilatory processes. However, standard conceptions of feature geometry (e.g., Clements and Hume 1995) only reinforce the disparity by integrating consonant and vowel features into a single geometry with vowel features as dependents of consonant place features. Such a configuration is intended to allow phonetically nonadjacent vowels to participate in harmony processes. More specifically, the assimilating vowel features are assumed to be on their own tier and would not incur line-crossing violations with intervening consonants. Those same geometries preclude place assimilation among nonadjacent consonants because the assimilating consonant features would incur a line-crossing violation with the intervening vowel.

To get around this problem, some have suggested that children's geometries may be simpler than those of adults, being configured with consonant and vowel features on entirely independent segregated tiers (e.g., McDonough and Myers 1991; Macken 1992). Such a proposal would allow phonetically nonadjacent consonants to be autosegmentally adjacent on the consonant tier and thus vulnerable to assimilation. This proposal would at least be consistent with standard locality expectations. Continuity considerations and richness of the base would, however, argue against any claims that children's geometries are inherently different from those of adults.

A possible alternative (similar to our solution to the prominence paradox) might be to postulate two competing markedness constraints that license particular geometric configurations in output candidates. For a discussion of how this might be done, see Dinnsen and Farris-Trimble (2008).

\section{Conclusion}

Our main purpose here was to show that children's error patterns are often restricted to word-initial position, merging a range of contrasts in that context, while maintaining those contrasts elsewhere within the word. The contextual restrictions on these processes are quite different from those ob- 
served for phonological processes in fully developed languages. Wordinitial position is generally presumed to be a strong, prominent context that resists mergers in fully developed languages; other contexts are weaker and are thus vulnerable to mergers. This discrepancy between developing and fully developed languages represents what we have termed the "prominence paradox" and would seem to undermine any claims of continuity (e.g., Pinker 1984). A theory such as optimality theory with its strong universal claims is especially challenged to reconcile the discrepancy between these developmental facts and those of fully developed languages.

Our solution introduced a new set of prominence-assigning markedness constraints that conflict with one another. One instance of this family (INITIALPROM) assigns or licenses prominence in the initial constituent of a syllable, foot, or prosodic word. The other, conflicting instance of this family (FINALPROM) assigns prominence to the complementary final constituent of those same prosodic categories. The ranking of these constraints determines which prosodic constituents are realized phonetically with prominence and thus likely to preserve contrasts. It was proposed that the default is for FINALPROM to be ranked over INITIALPROM. That ranking accounts for the early prominence of rhymes and final position and the emergence of many contrasts in those contexts. The reverse ranking of these constraints accounts for the prominence of onsets and initial position in fully developed languages. One likely trigger for the reranking of the prominenceassigning constraints was hypothesized to be a change in the size and organization of the lexicon in accord with experimental results revealing a developmental shift in the prominence of prosodic structures. Other factors as well may be responsible for reranking the prominence-assigning constraints, e.g., treatment that focuses the child's attention on word-initial position. With prominence determined from the ranking of the prominenceassigning constraints, the other positional faithfulness (or contextual markedness) constraints that depend on prominence can take advantage of that licensed prominence to preserve (or neutralize) a contrast.

One result of our proposal is that the constraint set can remain the same for developing and fully developed languages. As has been standard within optimality theory, the difference between these linguistic systems resides in the ranking of the constraints. Consequently, one of the most striking differences between developing and fully developed languages (vis-à-vis the prominence paradox) has in large part been obviated. The difference simply arises when developing phonologies rely on the default ranking of the universal prominence-assigning constraints, and fully developed languages rely on the reverse ranking of those constraints. 
Daniel A. Dinnsen and Ashley W. Farris-Trimble

\section{Notes}

Acknowledgments: We are especially grateful to Judith Gierut, John McCarthy, and an anonymous reviewer for their comments on earlier versions of this paper. We would also like to thank Nick Henriksen, Chris Green, and Traci Nagle for their assistance in the preparation of this paper. This work was supported by grants to Indiana University from the National Institutes of Health (NIH DC001694 \& DC00012).

1. Naturally, theories that do not sanction external evidence from development for the evaluation of its claims may not be troubled by this disparity. Aside from the disparity focused on in this paper, there are admittedly a number of other well established differences between developing and fully developed languages that continue to challenge claims of continuity. See, for example, the phenomenon of Consonant Harmony in child phonology (described briefly in §2.2, §2.3 and $\S 4.5)$, which is unattested in fully developed languages. Nevertheless, we will attempt to comply with the requirement of continuity in this paper because of the more rigorous test that it imposes.

2. This should not be taken to mean that all other featural distinctions were also merged in initial position. For an account of selective mergers, see the discussion of the various restrictions on Child 142's Consonant Harmony error pattern in $\S 3.2$.

3. There are some exceptions to this general claim motivated by typological considerations. For example, while the markedness constraint NoCoDA (Prince and Smolensky 1993/2004) bans closed syllables, a conflicting markedness constraint FINAL-C (McCarthy 1993) demands that a word-final syllable be closed. It is, however, important to note that these constraints conflict only in absolute word-final position. The asymmetric character of markedness constraints is also challenged by constraints making the same demand in complementary contexts. For example, while ONSET (Prince and Smolensky 1993/2004) bans onsetless syllables, FINAL-C requires that a syllable be closed word-finally. Importantly, there is no constraint that specifically demands that syllables be onsetless.

4. Because the prominence-assigning constraints conflict, they must be ranked. This is not unlike what must be assumed about other markedness constraints that conflict (e.g., constraints that align feet to the left or right edge of a word or that specify the foot type as trochaic/iambic). The default ranking of the prominenceassigning constraints is a separate empirical issue, which is one of the focal 
points of this paper. In any event, the ranking of the prominence-assigning constraints does not compromise in any way the presumed default ranking of markedness over faithfulness in the initial state. The prominence-assigning constraints conflict only with one another and do not conflict with any faithfulness constraints.

5. A contextual markedness alternative to positional faithfulness would rely on the prominence-assigning markedness constraints in much the same way. The difference would be that a context-sensitive markedness constraint would incorporate prominence by specifying that some feature is banned in the non-prominent part of a syllable, foot, or prosodic word. A context-free version of that markedness constraint would also be necessary to ban that same feature in all contexts. By ranking a context-free faithfulness constraint between these two markedness constraints, a contrast would be preserved in prominent contexts and merged in non-prominent contexts.

6. While we have formulated the prominence-assigning constraints in terms of prosodic categories, it might ultimately be more appropriate to align prominence with edges of prosodic, grammatical, or lexical categories. Because these various domains largely overlap in our data, additional research is needed to disambiguate the different predictions that would follow from these alternative formulations.

7. This is similar to the assumption that is often made regarding different syllabic parses of segmentally identical candidates.

8. The counterfeeding interactions observed in the case of Child 5T in §2.3 require special mechanisms to handle the associated opacity effects. For a discussion of the problems that opacity effects pose for optimality theory and for some possible solutions, see Dinnsen (2008).

\section{References}

\section{Baertsch, Karen S.}

2002 An optimality theoretic approach to syllable structure: The split margin hierarchy. Ph.D. diss., Department of Linguistics, Indiana University, Bloomington.

Barlow, Jessica A., and Judith A. Gierut

2008 A typological evaluation of the split margin approach to syllable structure in phonological acquisition. In Optimality Theory, Phonological Acquisition and Disorders, Daniel A. Dinnsen and Judith A. Gierut (eds.), 407-426. London: Equinox Publishing Ltd.

Beckman, Jill N.

1998 Positional faithfulness. Ph.D. diss., Department of Linguistics, University of Massachusetts, Amherst. 
Daniel A. Dinnsen and Ashley W. Farris-Trimble

Brooks, Patricia J., and Brian MacWhinney

2000 Phonological priming in children's picture naming. Journal of Child Language 27 (2): 335-366.

Charles-Luce, Jan, and Paul A. Luce

1990 Similarity neighbourhoods of words in young children's lexicons. Journal of Child Language 17: 205-215.

Clements, George N., and Elizabeth V. Hume

1995 The internal organization of speech sounds. In The Handbook of Phonological Theory, John A. Goldsmith (ed.), 245-306. Cambridge, MA: Blackwell.

Coady, Jeffry A., and Richard N. Aslin

2004 Young children's sensitivity to probabilistic phonotactics in the developing lexicon. Journal of Experimental Child Psychology 89: 183-213.

de Lacy, Paul V.

2002 The formal expression of markedness. Ph.D. diss., Department of Linguistics, University of Massachusetts, Amherst.

Dinnsen, Daniel A.

2008 A typology of opacity effects in acquisition. In Optimality Theory, Phonological Acquisition and Disorders, Daniel A. Dinnsen and Judith A. Gierut (eds.), 121-176. London: Equinox Publishing Ltd.

Dinnsen, Daniel A., and Ashley W. Farris-Trimble

2008 The prominence paradox. In Optimality Theory, Phonological Acquisition and Disorders, Daniel A. Dinnsen and Judith A. Gierut (eds.), 277-308. London: Equinox Publishing Ltd.

Dinnsen, Daniel A., and Judith A. Gierut

2008 Optimality Theory, Phonological Acquisition and Disorders. London: Equinox Publishing Ltd.

Echols, Catharine H., and Elissa L. Newport

1992 The role of stress and position in determining first words. Language Acquisition 2: 189-220.

Gierut, Judith A.

1985 On the relationship between phonological knowledge and generalization learning in misarticulating children. Ph.D. diss., Department of Speech and Hearing Sciences, Indiana University, Bloomington.

Goldman, Ronald, and Macalyne Fristoe

1986 Goldman-Fristoe Test of Articulation. Circles Pines, MN: American Guidance Service.

Iverson, Gregory, and Joseph C. Salmons

1995 Aspiration and laryngeal representation in Germanic. Phonology 12: 369-396. 
Kager, René

Optimality Theory. Cambridge: Cambridge University Press.

Kehoe, Margaret, and Geraldine Hilaire-Debove

2004 The structure of branching onsets and rising diphthongs: Evidence from acquisition. In Proceedings of the 28th Annual Boston University Conference on Language Development, 282-293. Somerville, MA: Cascadilla Press.

Kirk, Cecilia, and Katherine Demuth 2003 Onset/coda asymmetries in the acquisition of clusters. In Proceedings of the 27th Annual Boston University Conference on Language Development, 437-448. Somerville, MA: Cascadilla Press,.

Levelt, Clara C., and Ruben van de Vijver

2004 Syllable types in cross-linguistic and developmental grammars. In Constraints in Phonological Acquisition, René Kager, Joe Pater, and Wim Zonneveld (eds.), 204-218. Cambridge: Cambridge University Press.

Lleó, Conxita, and Michael Prinz

1996 Consonant clusters in child phonology and the directionality of syllable structure assignment. Journal of Child Language 23: 31-56.

Lombardi, Linda

1999 Positional faithfulness and voicing assimilation in optimality theory. Natural Language \& Linguistic Theory 17: 267-302.

Macken, Marlys A.

1992 Where's phonology? In Phonological Development: Models, Research, Implications, Charles A. Ferguson, Lise Menn, and Carol Stoel-Gammon (eds.), 249-269. Timonium, MD: York Press.

McCarthy, John J.

1993 A case of surface constraint violation. Canadian Journal of Linguistics 38: 169-195.

McDonough, Joyce, and Scott Myers

1991 Consonant harmony and planar segregation in child language. Unpublished ms., University of California, Los Angeles, and University of Texas, Austin.

Metsala, Jamie L., and Amanda C. Walley

1998 Spoken vocabulary growth and the segmental restructuring of lexical representations: Precursors to phonemic awareness and early reading ability. In Word Recognition in Beginning Literacy, Jamie L. Metsala and Linnea C. Ehri (eds.), 89-120. Hillsdale, NJ: Erlbaum. 
Munson, Benjamin, and Molly E. Babel

2005 The sequential cueing effect in children's speech production. Applied Psycholinguistics 26: 157-174.

Níchiosáin, Máire, and Jaye Padgett

2001 Markedness, segment realization, and locality in spreading. In Segmental Phonology in Optimality Theory: Constraints and Representations, Linda Lombardi (ed.), 118-156. Cambridge: Cambridge University Press.

Otomo, Kiyoshi, and Carol Stoel-Gammon

1992 The acquisition of unrounded vowels in English. Journal of Speech and Hearing Research 35: 604-616.

Parker, Steve

2001 Non-optimal onsets in Chamicuro: An inventory maximized in coda position. Phonology 18: 361-386.

Pater, Joe, and Adam Werle

2003 Direction of assimilation in child consonant harmony. The $\mathrm{Ca}$ nadian Journal of Linguistics/La Revue Canadienne de Linguistique 48: 385-408.

Pinker, Steven

$1984 \quad$ Language Learnability and Language Development. Cambridge, MA: Harvard University Press.

Pollock, Karen E., and Mary C. Berni 2003 Incidence of non-rhotic vowel errors in children: Data from the Memphis Vowel Project. Clinical Linguistics \& Phonetics 17 (4/5): 393-401.

Pollock, Karen E., and Nancy J. Keiser 1990 An examination of vowel errors in phonologically disordered children. Clinical Linguistics \& Phonetics 4: 161-178.

Prince, Alan, and Paul Smolensky

1993/2004 Optimality Theory: Constraint Interaction in Generative Grammar. Malden, MA: Blackwell.

Slobin, Dan I. 1973

Cognitive prerequisites for the development of grammar. In Studies of Child Language Development, Charles A. Ferguson and Dan I. Slobin (eds.), 175-208. New York: Holt, Rinehart, \& Winston.

Smit, Ann Bosma

1993 Phonologic error distributions in the Iowa-Nebraska Articulation Norms Project: Consonant singletons. Journal of Speech and Hearing Research 36: 533-547.

Smith, Bruce L., Karla K. McGregor, and Darcie Demille 2006 Phonological development in lexically precocious 2-year-olds. Applied Psycholinguistics 27: 355-375. 
Smith, Jennifer

2002

Phonological augmentation in prominent positions. Ph.D. diss., Department of Linguistics, University of Massachusetts, Amherst.

Smolensky, Paul

1996 The Initial State and 'Richness of the Base' in Optimality Theory (Tech. Rep. No. JHU-CogSci-96-4). Department of Cognitive Science, Johns Hopkins University.

Steriade, Donca

2001

Directional asymmetries in place assimilation: A perceptual account. In The Role of Speech Perception in Phonology, Elizabeth Hume and Keith Johnson (eds.), 219-250. San Diego: Academic Press.

Storkel, Holly L.

2002 Restructuring of similarity neighborhoods in the developing mental lexicon. Journal of Child Language 29: 251-274.

Walley, Amanda C., Jamie L. Metsala, and Victoria M. Garlock

2003

Spoken vocabulary growth: Its role in the development of phoneme awareness and early reading ability. Reading and Writing: An Interdisciplinary Journal 16 (1/2): 5-20. 